\title{
Preliminary assessment of differential expression of candidate genes associated with atherosclerosis
}

\author{
Joan Blin ${ }^{1}$, Zalinah Ahmad ${ }^{1 *}$, Lekhraj Rampal S/O Gyanchand Rampal ${ }^{2}$, \\ Norhafizah Mohtarrudin ${ }^{1}$, Abdul Karim Haji Tajudin ${ }^{3}$ \\ and Rohayu Shahar Adnan ${ }^{4}$ \\ ${ }^{1}$ Department of Pathology, Faculty of Medicine and Health Sciences, Universiti Putra Malaysia (UPM), \\ 43400 Serdang, Selangor, Malaysia \\ ${ }^{2}$ Department of Community Health, Faculty of Medicine and Health Sciences, Universiti Putra \\ Malaysia (UPM), 43400 Serdang, Selangor, Malaysia \\ ${ }^{3}$ Department of Forensic, Hospital Serdang, Jalan Puchong, 43000 Puchong, Selangor, Malaysia \\ ${ }^{4}$ Department of Forensic, Hospital Kuala Lumpur, 50586 Jalan Pahang, \\ Wilayah Persekutuan Kuala Lumpur
}

(Received 21 September 2012, accepted 18 June 2013)

Identifying susceptible genes associated with the pathogenesis of atherosclerosis (ATH) may contribute toward better management of this condition. This preliminary study was aimed at assessing the expression levels of 11 candidate genes, namely tumor protein (TP53), transforming growth factor, beta receptor II (TGFBR2), cysthathionenine-beta-synthase $(C B S)$, insulin receptor substrate 1 (IRS1), lipoprotein lipase (LPL), methylenetetrahydrofolate reductase (MTHFR), thrombomodulin (THBD), lecithin-cholesterol acyltransferase (LCAT), matrix metallopeptidase 9 (MMP9), low density lipoprotein receptor $(L D L R)$, and arachidonate 5-lipoxygenase-activating protein $(A L O X 5 A P)$ genes associated with ATH. Twelve human coronary artery tissues (HCATs) were obtained from deceased subjects who underwent post-mortem procedures. Six atherosclerotic coronary artery tissue (ACAT) samples representing the cases and non-atherosclerotic coronary artery tissue (NCAT) samples as controls were gathered based on predetermined inclusion and exclusion criteria. Gene expression levels were assessed using the GenomeLab Genetic Analysis System (GeXP). The results showed that LDLR, TP53, and MMP9 expression levels were significantly increased in ACAT compared to NCAT samples $(p<0.05)$. Thus, LDLR, TP53, and MMP9 genes may play important roles in the development of ATH in a Malaysian study population.

Key words: atherosclerosis, candidate genes, differential gene expression, GenomeLab Genetic Analysis System

\section{INTRODUCTION}

Cardiovascular disease (CVD) has been the leading cause of death in Malaysia for the last 45 years (Rampal et al., 2008). Atherosclerosis (ATH) is one of the underlying causes of CVD. Atherosclerosis (ATH) was formerly regarded as a lipid storage disease. It is known to be involved in ongoing inflammatory responses and processes (Libby et al., 2002). The development of ATH consists of three main phases, and inflammation plays a central role in all phases of atherosclerotic development (Spagnoli et al., 2007). In addition to inflammation, the deposition of cholesterol in the arterial wall also plays an important role in the pathogenesis of ATH. Different

Edited by Hiroyuki Toh

* Corresponding author. E-mail: zalinah@medic.upm.edu.my genes play important roles in the initiation and modulation of atherosclerotic disease through different mechanisms, either through up regulation or down regulation of these genes (Humphries and Ordovas, 2001). In our study, we aimed to determined the differential expressions of 11 candidate genes namely tumor protein (TP53), transforming growth factor, beta receptor II (TGFBR2), cysthathionenine-beta-synthase $(C B S)$, insulin receptor substrate 1 (IRS1), lipoprotein lipase ( $L P L)$, methylenetetrahydrofolate reductase (MTHFR), thrombomodulin (THBD), lecithincholesterol acyltransferase (LCAT), matrix metallopeptidase 9 (MMP9), low density lipoprotein receptor $(L D L R)$, and arachidonate 5-lipoxygenaseactivating protein $(A L O X 5 A P)$ genes associated with ATH development. Genes such as LCAT, LDLR, ALOX5AP, and $L P L$ are able to influence plasma cholesterol level. LCAT gene is a major determinant of plasma 
high-density lipoprotein (HDL) concentration. Previous study showed that heterozygosity of the $L C A T$ gene leads to LCAT enzyme deficiency, which is associated with both atherogenic lipid profile and vascular abnormalities (Ayyobi et al., 2004). A high level of plasma LDL on the other hand is a contributing factor for coronary artery disease (Tveten et al., 2012). Increased expression level of ALOX5AP in adipose tissue has also been linked with the risk of CVD (Kaaman et al., 2006). Meanwhile, proatherogenic role of LPL has been described previously in different studies (Werba et al., 2001; Mead et al., 1999).

Thrombomodulin, a product of THBD gene, is a glycoprotein receptor expressed on the endothelial cell surface and is involved in an anticoagulation pathway. Binding of thrombomodulin with thrombin activates protein $\mathrm{C}$, which in turn inhibits procoagulant pathway (Salomaa et al., 2001). Thus, reduced $T H B D$ expression could impair its function in coagulation cascade. TP53 is a tumor suppression protein 53 known to participate in diverse cellular stress, the cell cycle, and apoptosis (Levine et al., 2006). Apoptosis is a programmed cell death and known to cause a number of common and threatening vascular diseases, including atherosclerosis (Mallat and Tedgui, 2000). Meanwhile, TGF-beta superfamily plays a key role in the maintenance of normal blood vessel wall structure, and defects in genes encoding these superfamily members have been linked to a range of cardiovascular syndrome (Grainger, 2007).

Other genes such as MTHFR, CBS, MMP9, and IRS1 were also reported to be involved in the development of ATH. MTHFR and CBS enzymes are predominantly involved in folate and homocysteine metabolism. A defect in the gene encoding the MTHFR enzyme impairs the ability to produce folate. The reduction in folate activity leads to increased homocysteine levels in the blood, which is associated with an increased risk of developing ATH (Varga et al., 2005). Mild impairment of CBS function is also correlated with increased homocysteine concentration. The involvement of matrix metalloproteinases (MMPs) in the early stage of plaque development has been suggested by Loftus et al. (2002). The IRS1 gene however, has commonly been correlated with a higher risk of developing diabetes type 2 (Kovacs et al., 2003). However, previous study reported that the IRS1 gene also plays a role in CVD development (Baroni et al., 1999).

Atherosclerotic cardiovascular disease remains a growing public health burden in developed countries (Miller et al., 2007). Malaysia also has a hard time coping with the CVD burden every year. Much effort has been invested in screening, treating and preventing the disease. The high morbidity and mortality associated with ATH indicate the need for a better understanding of the underlying molecular events leading to disease etiology and progression.

With technological advancements, the world has been waiting for better ways of coping with this disease. One strategy for the ideal management of the disease is suggested to be the personalized medicine approach. However, this facet of medicine, which is moving closer to more precise, predictable and powerful medicine, can only be achieved through a thorough understanding of the disease genetics. The promise of personalized medicine, which allows us to provide better diagnoses, safer drug prescribing, and more effective treatment, depends on a detailed understanding of the genes and gene variants that contribute to disease susceptibility, progression (Seo et al., 2004) and treatment response. Thus, identifying the candidate genes associated with the development of the disease is a fundamental step.

The GenomeLab Genetic Analysis System (GeXP) is a novel technological platform for quantitative multiplexed gene expression analysis. GeXP is able to provide a better approach for the identification of multiple genes in a single reaction, which is important in studying a complex disease, such as atherosclerotic cardiovascular disease (Drew et al., 2011).

\section{MATERIALS AND METHODS}

Samples A total of 12 human coronary artery tissues (HCATs) were obtained from deceased subjects who had undergone a post-mortem procedure performed by an assigned medical officer in the Forensic Department of Hospital Serdang and Hospital Kuala Lumpur, Malaysia. The study was conducted after approval by the Ethics Committee of National Medical Research (NMRR-081592-2721), Ministry of Health, Malaysia, and the Ethics Committee of Faculty of Medicine and Health Sciences, Universiti Putra Malaysia (UPM). Six samples of atherosclerotic coronary artery tissue (ACAT) and six samples of non-atherosclerotic coronary artery tissue (NCAT), representing cases and controls, respectively, were gathered for the study. Our ACAT samples were defined as HCATs obtained from deceased subjects who died from ischemic heart disease (IHD) with the clear presence of an atheroma (mild, moderate or severe atheroma with $10 \%$ to $95 \%$ stenosis) within the tissue lining of left anterior descending (LAD) of left coronary artery tissue. Samples of NCAT were HCATs taken from deceased subjects who died from motorcycle vehicle accident (MVA) showing no atheroma at the lining of the same stated tissue region and were declared healthy by the pathologists involved in the post-mortem procedure. Other inclusion criteria for ACAT and NCAT samples included male Malaysian nationals only. All of the tissue samples were only taken from deceased subjects who had undergone the post-mortem within 24 hours between death and the execution of the autopsy. Subjects with conflicting diseases, such as diabetes and chronic inflammatory disease, were excluded from our study. The tissue characteristics were grossly examined and confirmed by a certified pathologist 
in the Forensic Department of both hospitals before being released to be used in this study. Microscopic examinations of ACAT samples were also performed to confirm the presence of atheroma, measuring the degree of stenosis, clinical complications, and the presence of superimposed thrombosis events. During the procedure, a $3.0 \mathrm{~cm}$ tissue sample was excised $1.2 \mathrm{~cm}$ away from the ostium of the LAD of left coronary artery. The tissue was cleaned by trimming excess fat tissues covering the artery using a sterile dissecting kit. Approximately $1.5 \mathrm{~cm}$ of each tissue was transferred into a $2 \mathrm{ml}$ tube containing $1.5 \mathrm{ml}$ of RNAlater solution, and the remaining $1.5 \mathrm{~cm}$ of tissue was preserved in formalin solution for microscopic examination with hematoxylin and eosin ( $\mathrm{H} \& \mathrm{E})$ staining. All of the samples were immediately stored at $4^{\circ} \mathrm{C}$ and transported to a laboratory in UPM as soon as possible. Table 1 shows demographic data of both ACAT and NCAT samples.

\section{Paraffin-embedded tissue and microscopic slide} preparations All formalin-fixed ACAT samples were cut longitudinally and processed using an automatic tissue processor (LEICA TP1020) for tissue dehydration. Next, the tissues were embedded by placing them in a mold filled with melted paraffin wax, and they were allowed to solidify. The paraffin-embedded tissues were then trimmed and sectioned into $3 \mu \mathrm{m}$ sections for microscopic slide preparation. All prepared microscopic slides underwent $\mathrm{H}$ \& $\mathrm{E}$ staining with an autostainer (Tissue-
Tek $^{\circledR}$ Prisma $\left.{ }^{\mathrm{TM}}\right)$. Next, the dried slides were mounted with DPX and examined under a microscope.

Total RNA isolation Total ribonucleic acid (RNA) was isolated from each $40 \mathrm{mg}$ of tissue sample using a PerfectPure RNA Tissue Kit (5-Prime, USA). The isolation steps were carried out according to the manufacturer's instructions. Briefly, tissue sample was immersed in lysis solution containing TCEP [tris (2-carboxyethyl) phosphine]. It was then thoroughly homogenized using Polytron ${ }^{\circledR}$ PT 1600E benchtop homogenizer (Kinematica,

Table 1. Characteristic of tissue samples

\begin{tabular}{lcc}
\hline \hline Characteristics & ACAT $(\mathrm{n}=6)$ & NCAT $(\mathrm{n}=6)$ \\
\hline Mean age (years) & $52.33 \pm 3.180$ & $34.67 \pm 4.372$ \\
Age range (years) & $47-58$ & $26-40$ \\
Sex & & \\
$\quad$ Male & 6 & 6 \\
Female & - & - \\
Cause of death & & - \\
IHD & 6 & 6 \\
Non-IHD & - & \\
\hline
\end{tabular}

(-) sign indicate no applicable data.

Result was represented as Mean \pm SD.

Ischemic heart disease (IHD).

Atherosclerotic coronary artery tissue (ACAT).

Non-atherosclerotic coronary artery tissue (NCAT).

Table 2. Summary table of candidate genes used for differential gene expressions analysis using GeXP

\begin{tabular}{|c|c|c|c|c|}
\hline Gene name & Gene locus & Gene product/description & Mechanism/Function & References \\
\hline Ezrin $^{\mathrm{a}}$ & $\mathrm{X} 51521$ & Ezrin & Housekeeping gene & - \\
\hline TP53 & NM_000546 & Tumor protein 53 & Inflammation & $\begin{array}{l}\text { Beiras-Fernandez } \\
\text { et al., } 2011\end{array}$ \\
\hline TGFBR2 & NM_003242 & $\begin{array}{l}\text { Transforming growth factor, } \\
\text { beta receptor II }\end{array}$ & Inflammation & $\begin{array}{l}\text { ten Dijke and } \\
\text { Arthur, } 2007\end{array}$ \\
\hline$C B S$ & L14577 & Cystathionenine-beta-synthase & Enzyme activity & Varga et al., 2005 \\
\hline IRS 1 & NM_005544 & Insulin receptor substrate 1 & Enzyme activity & Baroni et al., 1999 \\
\hline$L P L$ & NM_000237 & Lipoprotein lipase & Cholesterol transport & Werba et al., 2001 \\
\hline MTHFR & $\mathrm{BC} 053509$ & Methylenetetrahydrofolate reductase & Enzyme activity & Varga et al., 2005 \\
\hline$T H B D$ & NM_000361 & Thrombomodulin & Coagulation factors & Chan et al., 2006 \\
\hline$L C A T$ & NM_000229 & Lecithin-cholesterol acyltransferase & Cholesterol transport & Ayyobi et al., 2004 \\
\hline$A T P 5 O^{\mathrm{a}}$ & X83218 & $\begin{array}{l}\text { ATP synthase, } \mathrm{H}+\text { transporting, } \\
\text { mitochondrial } \mathrm{F} 1 \text { complex, O subunit }\end{array}$ & Housekeeping gene & - \\
\hline$M M P 9$ & NM_004994 & Matrix metallopeptidase 9 & Enzyme activity & Wang et al., 2011 \\
\hline$L D L R$ & NM_000527 & Low density lipoprotein receptor & Cholesterol transport & Tveten et al., 2012 \\
\hline$K n a r^{b}$ & - & Kanamycin resistance gene & Internal control & - \\
\hline$R P L P 0^{\mathrm{a}}$ & NM_001002 & Ribosomal protein, large, P0 & Housekeeping gene & - \\
\hline$A L O X 5 A P$ & NM_001629 & $\begin{array}{l}\text { Arachidonate 5-lipoxygenase- } \\
\text { activating protein }\end{array}$ & Cholesterol transport & Kaaman et al., 2006 \\
\hline
\end{tabular}

${ }^{\mathrm{a}}$ Gene used for normalization.

${ }^{\mathrm{b}}$ Internal control $K A N^{R}$ gene. 
Lucerne, Switzerland). Approximately $10 \mu \mathrm{l}$ of Proteinase K Solution (20 mg/ml) (Fermentas, Lithuania) was added into the lysate followed by vortexing and incubation on ice. Preclear column was used to remove large particulates. The RNA binding was then performed using Purification Column. The column was washed with Wash 1 solution before subjected to DNase treatment. After incubation, the column was washed with DNase Wash Solution. The washing step was repeated twice. Next, the Purification Column was transferred into a new collection tube and the sample was subjected to Wash 2 solution. This washing step was also repeated twice. The column was then transferred into a new collection tube. Elution Solution was added to the Purification Column to elute the RNA. The sample was then centrifuged to collect the eluted RNA sample into collection tube. The concentration and purity of yielded RNA were determined by the ratio of absorbance at 260 $\mathrm{nm}$ and $280 \mathrm{~nm}$ using a NanoDrop ND-1000 spectrophotometer (Nano-Drop Technologies, Wilmington, DE, USA).

Gene expression analysis The Beckman Coulter (Fullerton, CA, USA) GenomeLab Gene Expression Profiler (GeXP) genetic analysis system was used to study the gene expression pattern of 11 candidate genes that were proposed to mediate ATH development in humans.
These 11 candidate genes were selected based on previous reports on their associations with the risk of ATH development in human (Table 2). The GenomeLab GeXP Start Kit (GenomeLab), ThermoStart Taq DNA polymerase (Thermo Scientific), and capillary array for DNA separation (GenomeLab) were purchased from Beckman Coulter (Fullerton, CA, USA). The oligo (dT) multiplex primers were supplied by $1^{\text {st }}$ BASE.

Multiplex primer design Multiplex primer sets were designed using GenomeLab eXpress Profiler software by importing the accession number of the candidate genes into the eXpress Designer module of the software. The fragment sizes of primer pairs were designed in the range of 150 to 342 nucleotides to yield PCR products that had a 7 nucleotides difference from each other. Each primer was designed together with a universal primer sequence from 5' to 3' with the software. In addition to the candidate genes, three housekeeping genes (ezrin, ATP synthase, and ribosomal protein) were included for normalization. These genes were chosen because their product sizes were ideally distributed along the whole length of the panel. Primers were also designed to amplify a kanamycin resistance gene RNA transcript (supplied with the GeXP assay kit, Beckman Coulter, Fullerton, CA, USA) that was used to spike each reverse transcription reaction and served as

Table 3. Summary of reverse and forward primers sequences used in GeXP analysis

\begin{tabular}{|c|c|c|c|c|}
\hline $\begin{array}{l}\text { Gene } \\
\text { name }\end{array}$ & $\begin{array}{l}\text { Product } \\
\text { size }\end{array}$ & Left sequence ( 5 ' to $\left.3^{\prime}\right)$ & Right sequence (5' to $3^{\prime}$ ) & $\begin{array}{l}\text { Reverse primer } \\
\text { (nM) }\end{array}$ \\
\hline Ezrin $^{\mathrm{a}}$ & 150 & ${ }^{\mathrm{d}}$ GCCTAGAGGCTGACCGTATG & 'TGTGTATTCTGCAAGCTCCG & 4000 \\
\hline TP53 & 187 & ${ }^{\mathrm{d}}$ GTCAGAAGCACCCAGGACTT & ${ }^{\mathrm{e}} \mathrm{CTCCCAAACATCCCTCACAG}$ & 4000 \\
\hline$T G F B R 2$ & 201 & ${ }^{\mathrm{d}}$ CGGCTCCCTAAACACTACCA & eTATCCCCACAGCTTACAGGG & 4000 \\
\hline$C B S$ & 208 & daTTTGCGTGTTTGGGTTTTT & ${ }^{\mathrm{e}}$ GAGGGGAAATGATTGCTTCA & 4000 \\
\hline $\operatorname{IRS} 1$ & 215 & d'GGGTGCTGGCCTATTAGTGA & eTGCATTCATTGCCATTTGTT & 4000 \\
\hline$L P L$ & 222 & d'GCTGCAACAATCTGGGCTAT & ${ }^{\mathrm{e}}$ CACGGTGCCATACAGAGAAA & 4000 \\
\hline MTHFR & 243 & d'GAGGAAACAGCAGCCTCAAC & ${ }^{\mathrm{e}} \mathrm{GACAGCTCCCTCAGCAGTTC}$ & 4000 \\
\hline$T H B D$ & 250 & deGTGGGCTAGGGATGACTAA & eAAGTGGGGCTTGCTTCATAA & 4000 \\
\hline$L C A T$ & 257 & dTGGAAGGACCGCTTTATTGA & eAGCTGGGTGTGGAAATGAAC & 8000 \\
\hline$A T P 5 O^{\mathrm{a}}$ & 281 & dATTGAAGGTCGCTATGCCA & етCGACCATTTTCAGCAAGC & 8000 \\
\hline MMP9 & 293 & dAATCCTACTCCGCCTGCAC & eTCGCTGTCAAAGTTCGAGGT & 4000 \\
\hline$L D L R$ & 314 & deACCACGGTGGAGATAGTGA & ${ }^{\text {e} C T G T C T C G A G G G G T A G C T G T ~}$ & 4000 \\
\hline$K_{n a r}$ & 325 & dATCATCAGCATTGCATTCGATTCCTGTTTG & eATTCCGACTCGTCCAACATC & 1000 \\
\hline$R P L P O^{\mathrm{a}}$ & 330 & ${ }^{\mathrm{d}}$ CTGATGGGCAAGAACACCAT & 'еTGCCCTGGAGATTTTAGTG & 4000 \\
\hline$A L O X 5 A P$ & 342 & ${ }^{\mathrm{d}}$ GGTCTACACTGCCAACCAGAA & eTGGTGGTGGAGATCGTCTTT & 4000 \\
\hline
\end{tabular}

${ }^{\text {a}}$ Housekeeping gene.

${ }^{\mathrm{b}}$ Internal control.

${ }^{\mathrm{c}}$ Housekeeping gene used for normalization.

'Universal left sequence $=$ 5'-AGGTGACACTATAGAATA...-3'.

'Universal right sequence $=5$ '-GTACGACTCACTATAGGGA...-3'.

Note: Universal left and right sequence tags are linked to the left and right primer sequence of each gene, respectively. 
an internal reaction integrity control (Vansant et al., 2006; Chen et al., 2007; Ismail et al., 2010). Finally, all of the primers were pooled for GeXP multiplex analysis. The genes and primer sequences are listed in Table 2 and Table 3.

Reverse transcription Semi-quantitative reverse transcription polymerase chain reaction (RT-PCR) was performed using the GenomeLab GeXP Start Kit (GenomeLab) from Beckman Coulter (Fullerton, CA, USA). A total of $250 \mathrm{ng}$ total RNA per well was used in the RT-PCR. A pool of all reverse primers was prepared at final concentrations of $4.0 \mu \mathrm{M}$ to $8.0 \mu \mathrm{M}$ in a final volume of $500 \mu \mathrm{l}$. Three different controls were performed for RT-PCR, including a reverse transcriptase minus (RT Minus) control (without reverse transcriptase), a no template control (without RNA) and kanamycin resistance gene RNA amplification as an internal reaction integrity control during cDNA synthesis. A total reaction volume of $20 \mu \mathrm{l}$ for each sample was prepared and mixed gently followed by brief centrifugation. The RT-PCR mixture was incubated in a thermal cycler with the following program: $1 \mathrm{~min}$ at $48^{\circ} \mathrm{C}, 60 \mathrm{~min}$ at $42^{\circ} \mathrm{C}$, and $5 \mathrm{~min}$ at $95^{\circ} \mathrm{C}$, with a final hold at $4^{\circ} \mathrm{C}$.

Polymerase chain reaction Polymerase chain reaction (PCR) was then performed on each sample by adding $9.3 \mu \mathrm{l}$ of cDNA from each previous RT-PCR to a pool of all forward primers at $0.2 \mu \mathrm{M}$ in a final reaction volume of $20 \mu \mathrm{l}$ containing $4 \mu \mathrm{l}$ of $5 \mathrm{X}$ PCR buffer, $4 \mu \mathrm{l} 25 \mathrm{mM} \mathrm{MgCl}_{2}$ (Thermo-Start) and $0.7 \mu$ Thermo-Start DNA Polymerase (7 U). PCR was performed in a thermal cycler under the following conditions: $10 \mathrm{~min}$ at $95^{\circ} \mathrm{C}$, followed by 35 cycles of $30 \mathrm{~s}$ at $94^{\circ} \mathrm{C}, 20 \mathrm{~s}$ at $55^{\circ} \mathrm{C}$, and $1 \mathrm{~min}$ at $68^{\circ} \mathrm{C}$, with a final hold at $4^{\circ} \mathrm{C}$.

Fragment analysis Sample loading solution (SLS) was prepared by adding $37.5 \mu \mathrm{l}$ of SLS buffer (Beckman Coulter, Fullerton, CA, USA) and $0.5 \mu \mathrm{l}$ of CEQ DNA size standard-400 (Beckman Coulter, Fullerton, CA, USA) to
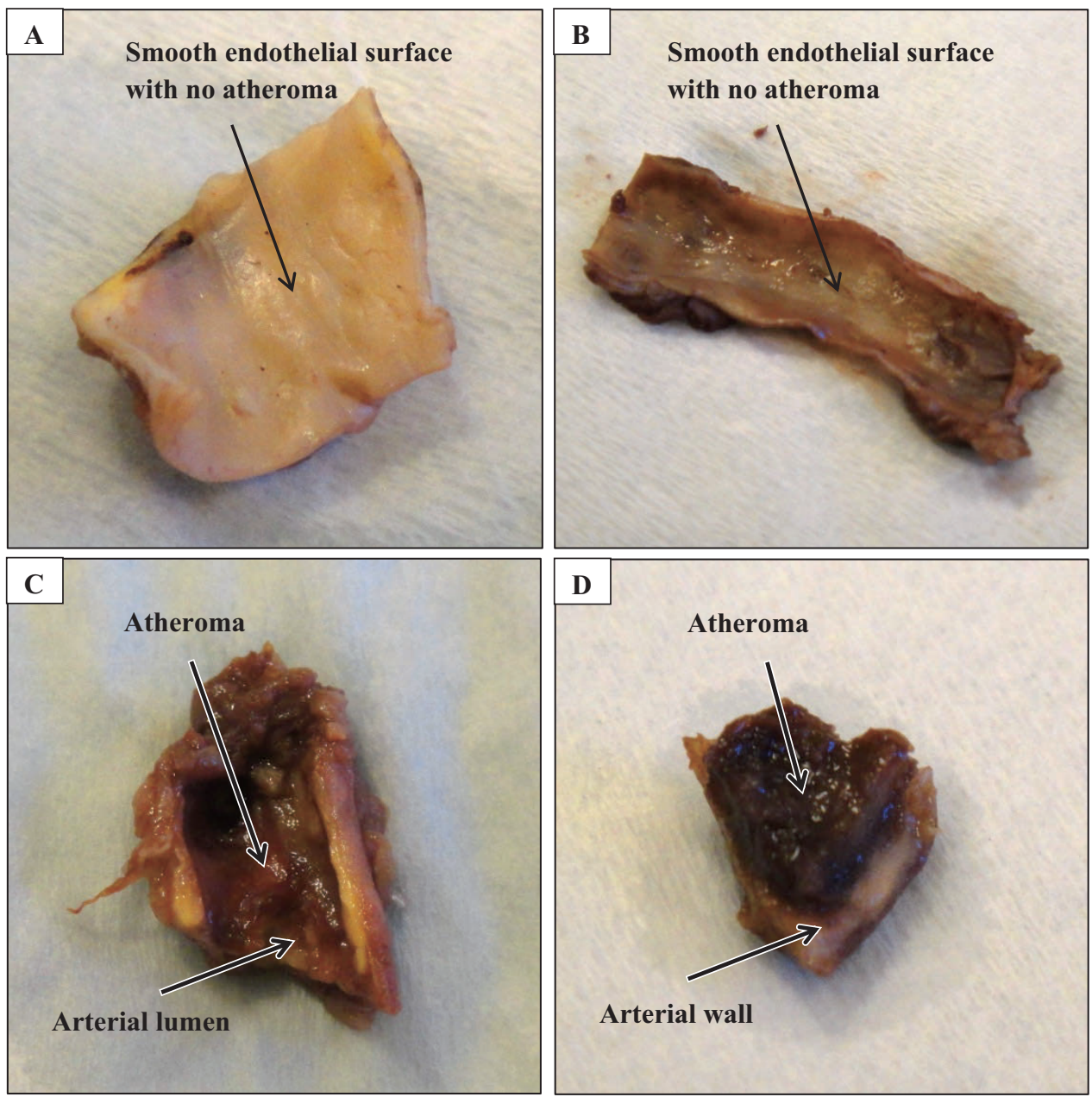

Fig. 1. Gross examinations of left coronary artery tissues obtained from deceased subjects. A \& B: NCAT samples with no evidence of atheroma formation. C \& D: ACAT samples with the presence of severe atheroma $(>50 \%$ of stenosis), composed of fibrous plaque. 
each reaction. Next, $2.0 \mu \mathrm{l}$ of each PCR product was added into each well of a Beckman 96-well CEQ electrophoresis plate containing the SLS mixture. GeXP separates PCR products based on size through capillary gel electrophoresis. The dye signal strength was then measured in arbitrary units of optical fluorescence, which was defined as the fluorescent signal minus background (Ismail et al., 2010). The GeXP software matches each fragment peak with the appropriate gene. It then reports the peak height and area-under-the-curve (AUC) for all peaks in the electropherogram (Rai et al., 2009). Gene expression data were gathered and normalized to the internal control gene (KanR) with AUC set at 1 and evaluated with GenomeLab GeXP Quant Tool software (Beckman Coulter, Fullerton, CA, USA). For this data set, we chose $A T P 5 O$ as our housekeeping normalization gene due to its ideal expression level. The data were then imported into the analysis module of eXpress Profiler software for gene normalization using our chosen ATP5O housekeeping gene and for subsequent analysis. Finally, all multiplexes were combined into one Excel data file for further statistical analysis.

Statistical analysis Statistical analysis was carried out using Statistical Package for Social Sciences (SPSS) version 17.0. Student's $t$-test was performed to compare the mean expression levels of each candidate gene between ACAT and NCAT samples. Significant differences were obtained at $p$ values less than $0.05(p<0.05)$.
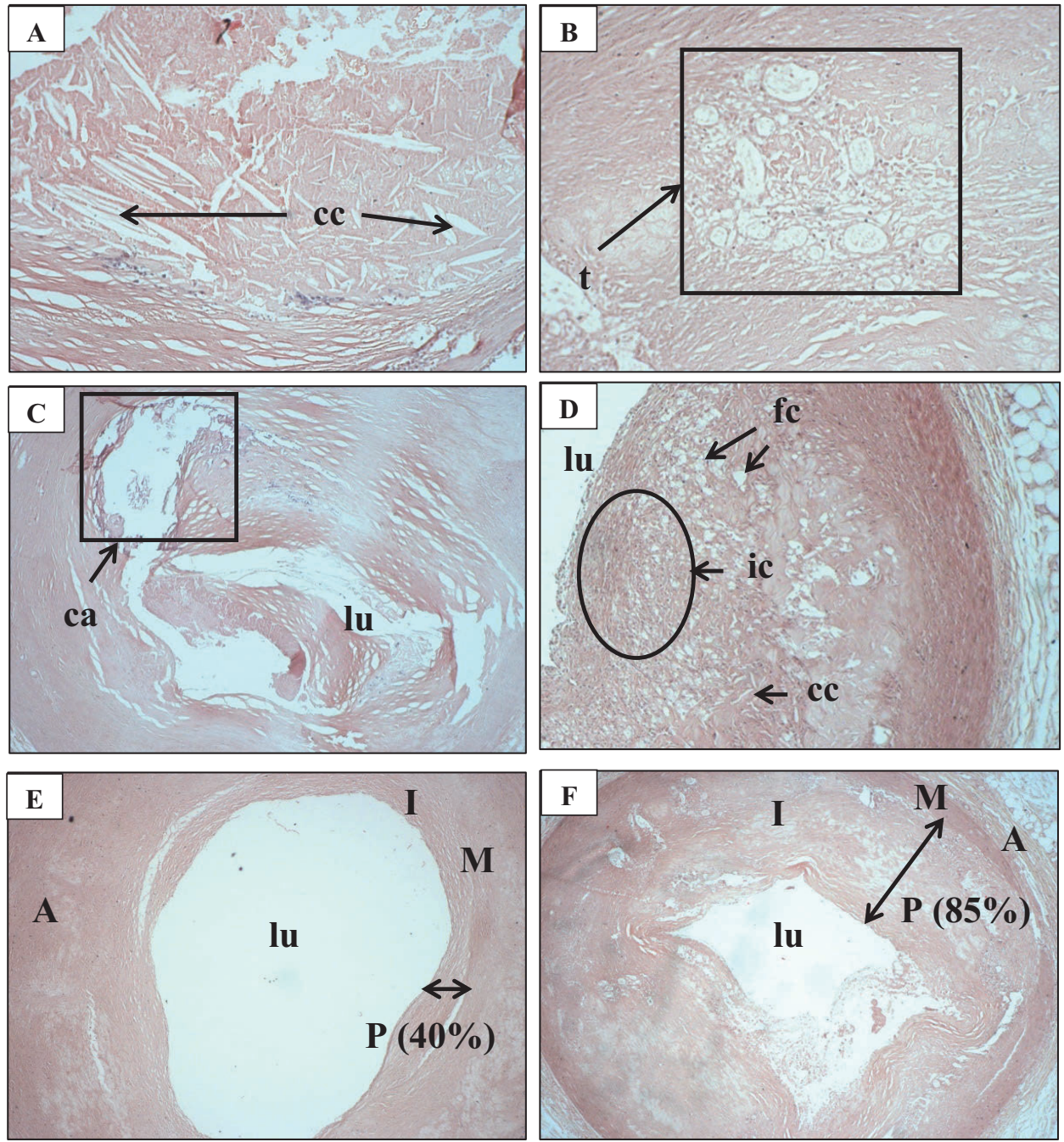

Fig. 2. A. The open, needle-like spaces in the atheromatous plaque are cholesterol clefts (cc). B. This section of coronary artery demonstrates remote thrombosis $(t)$ with recanalization and organization. C. There is a large area of calcification (ca) on the upper left, which appear bluish on this H \& E stain. D. This section of unstable atheroma shows numerous foam cells (fc), cholesterol clefts (cc) and the presence of a few dark blue inflammatory cells scattered within the atheroma. E. Stable atheroma with $40 \%$ stenosis. F. Unstable atheroma with $85 \%$ stenosis. Note: inflammatory cells (ic), lumen (lu), atheroma plaque (P), intima layer (I), media layer (M), adventitia layer (A), arrow indicating the thickness of atheroma; original magnification $\times 40(\mathrm{C}, \mathrm{E}, \& \mathrm{~F})$; original magnification $\times 100(\mathrm{~A} \& \mathrm{D})$; original magnification $\times 200(\mathrm{~B})$. 


\section{RESULTS}

Pathological cardiac findings by gross examinations Gross examination findings showed the presence of severe atheroma in ACAT samples. These tissues were less elastic in structure compared to NCAT samples. In the most severe cases, the tissues were hardened, with abundant plaque accumulating along the arterial wall. NCAT samples, however, showed a clean lumen, with no atheroma observed along the wall of the coronary artery.
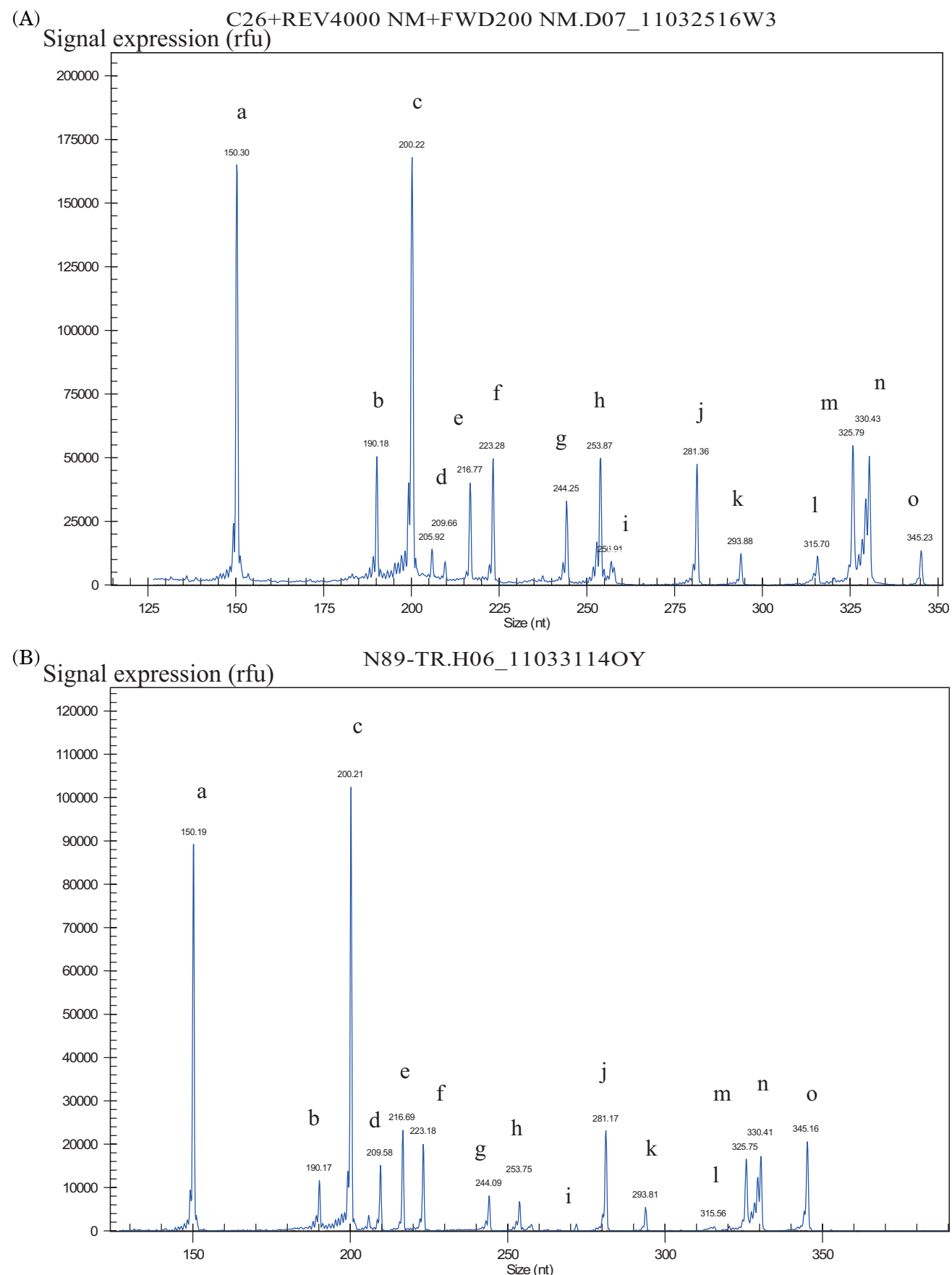

Fig. 3. Representative electropherograms showing quantitative multiplex GeXP of candidate genes related to atherosclerosis using custom design GeXP multiplex assay. A: Candidate genes expression in atherosclerotic coronary artery tissue (ACAT) samples. B: Candidate genes expression in non-atherosclerotic coronary artery tissue (NCAT) samples. Housekeeping genes (a: Ezrin; j: ATP5O; n: RPLP0). Candidate genes (b: TP53; c: TGFBR2; d: CBS; e: IRS1; f: LPL; g: MTHFR; h: THBD; i: LCAT; k: MMP9; l: LDLR; o: ALOX5AP). Internal control gene (m: Knar). The size of detected amplicons in ACAT (A) and NCAT samples (B) are shown. The amplicons sizes were varying in two to three nucleotides from the actual product size. 
In addition, the tissues were more elastic in structure than ACAT samples. Fig. 1 shows the gross examination images of ACAT and NCAT samples.

Pathological cardiac findings by microscopic examinations The ACAT samples consisted of both stable and unstable atheromas, with $40 \%$ to $85 \%$ stenosis. Stable atheromas were composed of a thick fibrous cap (> $65 \mu \mathrm{m}$ thickness), with no inflammatory cells within the plaques. In contrast, unstable atheromas (as shown in Fig. 1, C and D) were characterized by fibrous caps that were less than $65 \mu \mathrm{m}$ thick, and the plaques were mainly composed of inflammatory cells, foaming macrophages, and necrotic cells. Fig. 2 shows stable and unstable atheromas with different degrees of stenosis and the presence of inflammatory cells, foaming macrophages, cholesterol clefts, calcification, and an old thrombus with evidence of organization and recanalization in the atheroma tissues.

Differential expression of candidate genes analysis in ACAT and NCAT samples Prior to the quantitative analysis, optimization procedures were carried out for RT-PCR and GeXP analysis protocols. Each genespecific primer pair was first tested in a single-plex reaction before analysis of the multiplex primer mix of the 11 selected gene-specific primers was carried out. This initial experiment was performed to confirm that no false fragments were produced and that only a single peak of the expected size was generated from each of the single-plex reaction analyses. During the multiplex assay, it was initially found that some of the candidate genes yielded low signal peaks in the gene panel. Thus, gene-specific reverse primer concentrations were optimized to improve detection in the multiplex reactions. The primer concentrations that gave optimal signal detection are listed in Table 3. Although we included three housekeeping genes in the multiplex reaction mixture, only two genes (e.g $A T P 5 O$ and $R P L P O)$ were chosen for normalization based on their expression levels suitability (Fig. 3). ATP5O normalized data revealed significantly altered expression of three candidate genes (LDLR, TP53, and MMP9) (Fig. 4A). LDLR, TP53, and MMP9 expressions were significantly up-regulated in ACAT samples. ATP5O normalized data also indicated up-regulation of TGFBR2, $C B S$, MTHFR, THBD, LCAT, and ALOX5AP gene expression in ACAT samples. However this data was not significant. Down-regulation of IRS1 and LPL expressions indicated in this analysis was also not significant. Meanwhile, $R P L P O$ normalized data revealed fewer significantly altered expressions in the candidate genes when compared to ATP5O normalized data (Fig. 4B). The RPLPO normalized data demonstrated that MMP9 and TP53 expressions were significantly up-regulated in ACAT samples. Other genes showed broadly similar expression to those in ATP5O normalized data, with no signifi-

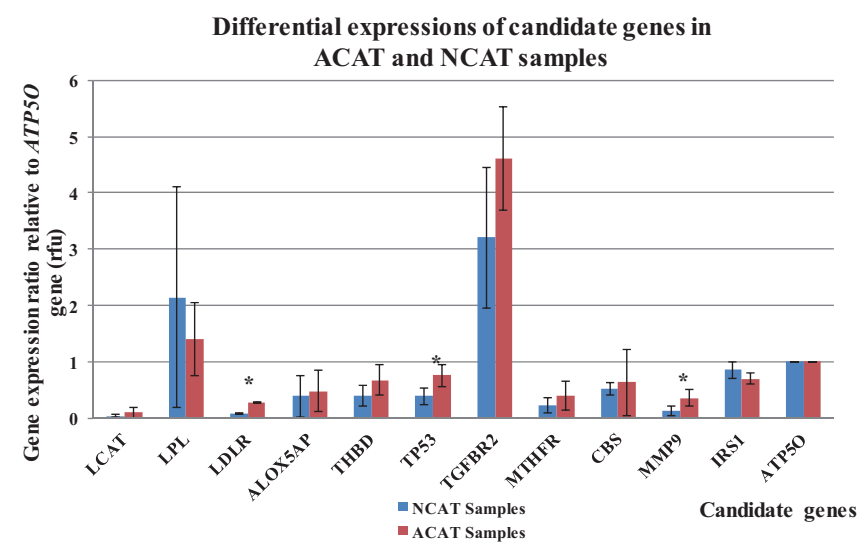

(A)

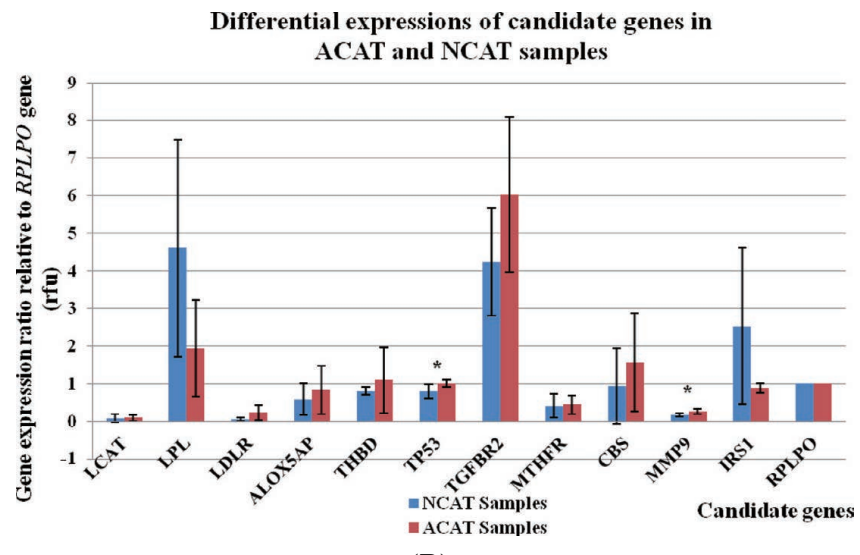

(B)

Fig. 4. Differential expression of 11 candidate genes assessed using GeXP analysis. Gene expression is normalized to two housekeeping genes $A T P 5 O$ (A) and $R P L P O$ (B) respectively. Each value was represented as Mean \pm SD. * indicates significance at $p<0.05$.

cant result obtained. Table 4 displays the summary information of expression pattern from data being normalized by both housekeeping genes. This table compares ATP5O and RPLPO normalized data where expression pattern of candidate genes was marked together with its differential expression in fold change.

\section{DISCUSSION}

The aim of this study was to assess the differential expression of 11 candidate genes associated with the risk of developing ATH in a Malaysian study population. These genes are important in physiological cellular and metabolic functions, such as the cholesterol transport pathway, the coagulation cascade, the inflammatory process and enzyme activities, thus, were classified into four different mechanisms or pathways based on their functions in the human body. Peripheral blood is the easiest source of RNA for differential expression of candidate genes experiments in both human and animal models. However, gene expression studies have been carried out 
Table 4. Gene expression pattern using ATP5O and RPLPO normalized data

\begin{tabular}{|c|c|c|c|c|}
\hline \multirow{2}{*}{$\begin{array}{l}\text { Candidate } \\
\text { genes }\end{array}$} & \multicolumn{2}{|c|}{ ATP5O normalized data } & \multicolumn{2}{|c|}{$R P L P O$ normalized data } \\
\hline & $\begin{array}{c}\text { Gene } \\
\text { expression }\end{array}$ & $\begin{array}{c}\text { Fold } \\
\text { change }\end{array}$ & $\begin{array}{c}\text { Gene } \\
\text { expression }\end{array}$ & $\begin{array}{c}\text { Fold } \\
\text { change }\end{array}$ \\
\hline TP53 & $\uparrow *$ & 1.963 & $\uparrow *$ & 1.245 \\
\hline TGFBR2 & $\uparrow$ & 1.439 & $\uparrow$ & 1.421 \\
\hline$C B S$ & $\uparrow$ & 1.202 & $\uparrow$ & 1.672 \\
\hline IRS1 & $\downarrow$ & -0.825 & $\downarrow$ & -0.352 \\
\hline$L P L$ & $\downarrow$ & -0.652 & $\downarrow$ & -0.422 \\
\hline$M T H F R$ & $\uparrow$ & 1.773 & $\uparrow$ & 1.103 \\
\hline$T H B D$ & $\uparrow$ & 1.701 & $\uparrow$ & 1.728 \\
\hline$L C A T$ & $\uparrow$ & 2.647 & $\uparrow$ & 1.134 \\
\hline$M M P 9$ & $\uparrow *$ & 1.773 & $\uparrow *$ & 1.538 \\
\hline$L D L R$ & $\uparrow *$ & 3.913 & $\uparrow$ & 4.018 \\
\hline$A L O X 5 A P$ & $\uparrow$ & 1.238 & $\uparrow$ & 1.415 \\
\hline
\end{tabular}

Note: Data normalized to ATP5O and RPLPO genes. (* indicates significance at $p<0.05 ; \uparrow$ indicates up-regulated gene; $\downarrow$ indicates down-regulated gene; and negative (-) sign indicates decrease in fold change.

recently using tissue samples instead for a better understanding of the gene expression pattern of a disease at a specific location. In our study, coronary artery tissue was used to study the differential expression of candidate genes in disease (ACAT) and non-disease (NCAT) samples. In this study, pathological cardiac findings for each tissue were confirmed by performing gross and microscopic examinations. These steps were crucial to ensure that all of the ACAT samples used in our study showed evidence of atheroma within the stated tissue region. Human coronary artery tissues were selected based on predetermined criteria as mentioned in the methods section. Subjects with conflicting diseases, such as diabetes and chronic inflammatory disease, were excluded from our study because complications of diabetes usually lead to CVD; thus, the possibility that the subject had already developed an initial stage of CVD. ATH itself is also closely linked to a disease of the inflammatory response. Patients with a chronic inflammatory disease might have a similar pattern of differential gene expression as those suffering from atherosclerotic disease. By taking these into account, we tried to avoid any potential interference in our study.

An ideal gene for normalization is one that shows consistency in expression levels and whose signal intensity is approximately half of the intensity of the candidate genes. For this matter, ATP50 and RPLPO were chosen for data normalization and subsequent statistical analysis in this study. In our study, four candidate genes related to cholesterol transport were assessed for their expression levels in ACAT and NCAT samples. Our findings showed that cholesterol transport-related genes, such as $L C A T, L D L R$, and ALOX5AP, were expressed from one-to four-fold higher in ACAT compared to NCAT samples. The $L P L$ gene, in contrast, showed a slight down-regulation in atherosclerotic tissue of less than onefold (Table 4). However, these differences were not statistically significant. Although the role of the LCAT gene in ATH is controversial, a previous study showed that heterozygocity of the LCAT gene leads to LCAT enzyme deficiency, which is associated with both atherogenic lipid profile and vascular abnormalities (Ayyobi et al., 2004). According to our findings, the LCAT expression pattern was slightly increased in ACAT samples compared to NCAT samples. However, there was no significant difference in this pattern. This result seemed to contradict the previous theory on $L C A T$ expression levels being related to ATH (Hoeg et al., 1996). Kaaman et al. (2006) reported that the mRNA expression level of ALOX5AP in subcutaneous adipose tissue was increased in obese subjects and normalized following weight reduction. They suggested that the increased gene expression of ALOX5AP in adipose tissue was associated with an insulin-resistance phenotype, which was a risk factor for CVD. In our findings, there was only a slight increase in the ALOX5AP expression level in ACAT samples compared to NCAT samples. However, the significant increase in the $L D L R$ gene expression profile suggested its positive association with ATH development. This finding corroborates the ideas of Salazar et al. (2000) who demonstrated that the $L D L R$ gene polymorphism is associated with coronary artery disease (CAD) in Brazilian Caucasian women. The $L D L R$ gene plays an important role in mediating the cellular uptake of plasma low-density lipoprotein (LDL). In general, high LDL levels and low HDL levels are associated with a high risk of CVD. Thus, the over-expression of the $L D L R$ gene in this study may be an indicator that this gene could be associated with an increased risk of developing ATH in Malaysia.

Factors such as thrombin and fibrin have been known to contribute to ATH initiation and progression via the activation of tissue factor in the coagulation cascade (Marutsuka et al., 2005). Thrombin and fibrin act as procoagulant agents during blood clotting. One of the most frequent events in patients with acute myocardial infarction is blood clot formation resulting from plaque disruption in coronary arteries. Plaque disruption normally leads to the formation of a thrombus, which is carried by the blood stream and could cause vessels to become plugged. This condition reduces the blood supply to the heart, which leads to unstable angina, acute coronary syndrome, and in the worst scenario, sudden death. Thus, an endogenous anticoagulant factor, such as protein $\mathrm{C}$, is important in maintaining the homeostatic balance in the coagulation cascade to prevent thromboembolic disease (Ohlin et al., 2004). Thrombomodulin, a product of the $T H B D$ gene, is known to play an opposite role to 
thrombin and fibrin. During the coagulation cascade, thrombomodulin binds to thrombin to activate protein C. Activated protein $\mathrm{C}$ inhibits the procoagulant pathway by degrading activated factors V and VIII (Salomaa et al., 2001). The thrombomodulin-thrombin complex changes the activity of thrombin from pro-coagulation to anti-coagulation (Zhao et al., 2005). The inhibition of further thrombin formation in the coagulation cascade by the thrombomodulin-thrombin complex thereby limits blood coagulation. In addition, this complex inhibits fibrinolysis by cleaving thrombin-activatable fibrinolysis inhibitor (TAFI) into its active form. Because thrombomodulin is an important link between coagulation and fibrinolysis, the down-regulation of its gene expression level could impair its function in anti-coagulation. In our study, we assessed the expression level of the THBD gene in both ACAT and NCAT samples to determine its association with ATH development. We found a slight increase in THBD gene expression in ACAT compared to NCAT samples, although this increase was not significant. The up-regulated pattern of the $T H B D$ gene level in our study seemed to clash with the theory of $T H B D$ function. However, the conflicting data might be due to the small sample size.

Two of the candidate genes in this study are inflammation-related genes. In our findings, both TP53 and TGFBR2 showed higher expression levels in ACAT compared to NCAT samples. Although the difference in TGFBR2 gene expression in ACAT and NCAT samples was not significant, the expression of the TP53 gene was significantly increased in ACAT compared to NCAT samples. Its expression level is low in normal cells but high in transformed cell lines. We found in our study that the TP53 level was up regulated in ACAT, suggesting that the TP53 gene contributes to the progression of ATH development. These findings further support the idea of Beiras-Fernandez et al. (2011), who suggested that polymorphisms in the TP53 gene increased the risk of CAD progression. A previous study also suggested that cellular death by apoptosis occurs within atherosclerotic lesions (Lesauskaite et al., 2003). Thus, because the TP53 gene can promote apoptosis, it is not surprising that the loss of TP53 functions leads to an increased progression of ATH.

In a complex disease such as ATH, enzyme activities greatly influence the complex cascade of ATH development. MTHFR, CBS, MMP9, and IRS1 genes were assessed for their association with ATH development due to their involvement in the important pathways within atherosclerotic lesion development. We found an increase in MTHFR and CBS expression in ACAT compared to NCAT samples. However, due to limited sample size, we were unable to demonstrate significant differences in their expression between the two groups. The expression of the MMP9 gene was significantly increased in ACAT compared to NCAT samples. In normal adult tissue, the expression of matrix metalloproteinases (MMPs) is usually low. Although a slight down-regulation of IRS1 gene expression was noted, there was no significant difference in the gene expression level reported in this study (less than one-fold decrease). Matrix metalloproteinases (MMPs) are a family of 24 proteins with different substrate specificities. They include extracellular matrix (ECM) and cell surface proteins (Newby, 2007). In normal adults, the expression of MMPs is low. However, during physiological and pathological remodeling processes, their expression is up-regulated. The increased of MMPs expressions has also been reported within atherosclerotic plaques (Sukhova et al., 1999). Thus, our present findings seem to be consistent with other research, which found a similar pattern of MMP9 expression in atherosclerotic tissues. As mentioned earlier, the slight decrease in IRS1 gene expression level in ATH tissue was not significant. Nevertheless, the pattern of IRS1 gene expression was in agreement with previous studies performed by other researchers. This insignificance could most likely be due to our small sample size.

In conclusion, our preliminary findings showed that the LDLR, TP53, and MMP9 genes were possible predictors for susceptibility factors in developing ATH. Although the other candidate genes had been suggested to have an association with CAD in previous studies, they did not show a significant association in this present study. The main reason for this result is most likely due to the relatively small number of ACAT and NCAT samples, which limited our findings. Further studies with a larger sample size are recommended to conclude the influence of these genes on ATH progression with certainty. This will help in revealing a more significant association of candidate genes associated with ATH development in a Malaysian study population.

We thank all the staff and forensic pathologists at the Forensic Department of Hospital Serdang, Serdang, Selangor, and Hospital Kuala Lumpur, Kuala Lumpur, Malaysia, respectively, for help in supplying the samples involved in this study. Special appreciation is also extended to Miss Chow Woan Yun from Beckman Coulter for her excellent technical assistance. This study was supported by the IRPA 06-02-04-0482 research grant.

\section{REFERENCES}

Ayyobi, A. F., McGladdery, S. H., Chan, S., Mancini, G. B. J., Hill, J. S., and Frohlich, J. J. (2004) Lecithin: cholesterol acyltransferase (LCAT) deficiency and risk of vascular disease: 25 year follow-up. Atherosclerosis 177, 361-366.

Baroni, M. G., D’Andrea, M. P., Montali, A., Pannitteri, G., Barillà, F., Campagna, F., Mazzei, E., Lovari, S., Seccareccia, F., Campa, P. P., et al. (1999) A common mutation of the insulin receptor substrate- 1 gene is a risk factor for coronary artery disease. Arterioscler. Thromb. Vasc. Biol. 19, 2975-2980.

Beiras-Fernandez, A., Angele, M. K., Koutang, C., Lohse, P., Reichart, B., Lohse, P., and Eifert, S. (2011) Genetic polymorphisms of TP53 and FAS promoter modulate the progression of coronary artery disease after coronary artery 
bypass grafting: a gender-specific view. Inflamm. Res. 60, $439-445$.

Chan, S., Chen, J., Li, Y., Lin, L., and Tsai, L. (2006) Increasing post-event plasma thrombomodulin level associates with worse outcome in survival of acute coronary syndrome. Int. J. Cardiol. 111, 280-285.

Chen, R., Vansant, G., Oades, K., Pickering, M., Wei, J. S., Song, Y. K., Monforte, J., and Khan, J. (2007) Diagnosis of the small round blue cell tumors using multiplex polymerase chain reaction. J. Mol. Diagn. 9, 80-88.

Drew, J. E., Mayer, C. D., Farquharson, A. J., Young, P., and Barrera, L. N. (2011) Custom design of GeXP multiplexed assay used to assess expression profiles of inflammatory gene targets in normal colon, polyp, and tumor tissue. J. Mol. Diagn. 13, 233-242.

Grainger, D. J. (2007) TGF- $\beta$ and atherosclerosis in man. Cardiovasc. Res. 74, 213-222.

Hoeg, J. M., Santamarina-Fojo, S., Berard, A. M., Cornhill, J. F., Herderick, E. E., Feldman, S. H., Haudenschild, C. C., Vaisman, B. L., Hoyt, R. F., Jr., Demosky, S. J., et al. (1996) Overexpression of lecithin: cholesterol acyltransferase in transgenic rabbits prevents diet-induced atherosclerosis. Proc. Natl. Acad. Sci. USA. 93, 11448-11453.

Humphries, S. E., and Ordovas, J. M. (2001) Genetics and atherosclerosis: Broadening the horizon. Atherosclerosis 154, 517-519.

Ismail, M., Al-Naqeep, G., and Chan, K. W. (2010) Nigella sativa thymoquinone-rich fraction greatly improves plasma antioxidant capacity and expression of antioxidant genes in hypercholesterolemic rats. Free Radical Biology \& Medicine 48, 664-672.

Kaaman, M., Rydén, M., Axelsson, T., Nordström, E., Sicard, A., Bouloumié, A., Langin, D., Arner, P., and Dahlman, I. (2006) ALOX5AP expression, but not gene haplotypes, is associated with obesity and insulin resistance. Int. J. Obes. 30, 447-452.

Kovacs, P., Hanson, R. L., Lee, Y. H., Yang, X., Kobes, S., Permana, P. A., Bogardus, C., and Baier, L. J. (2003) The role of insulin receptor substrate-1 gene (IRS1) in type 2 diabetes in Pima Indians. Diabetes 52, 3005-3009.

Lesauskaite, V., Ivanoviene, L., and Valanciute, A. (2003) Programmed cellular death and atherogenesis: from molecular mechanisms to clinical aspects. Medicina 39, 529534.

Levine, A. J., Hu, W., and Feng, Z. (2006) The P53 pathway: what questions remain to be explored? Cell Death Differ. 13, 1027-1036.

Libby, P., Ridker, P. M., and Maseri, A. (2002) Inflammation and atherosclerosis. Circulation 105, 1135-1143.

Loftus, I. M., Naylor, A. R., Bell, P. R. F., and Thompson, M. M. (2002) Matrix metalloproteinases and atherosclerotic plaque instability. Brit. J. Surg. 89, 680-694.

Mallat, Z., and Tedgui, A. (2000) Apoptosis in the vasculature: mechanisms and functional importance. Br. J. Pharmacol. 130, 947-962.

Marutsuka, K., Hatakeyama, K., Yamashita, A., and Asada, Y. (2005) Role of thrombogenic factors in the development of atherosclerosis. J. Atheroscler. Thromb. 12, 1-8.

Mead, J. R., Cryer, A., and Ramji, D. P. (1999) Lipoprotein lipase, a key role in atherosclerosis? FEBS Lett. 462, 1-6.

Miller, D. T., Ridker, P. M., Libby, P., and Kwiatkowski, D. J. (2007) The path from genomics to therapeutics. J. Am. Coll. Cardiol. 49, 1589-1599.

Newby, A. C. (2007) Role of metalloproteinases in plaque rupture. Int. J. Gerontol. 1, 103-111.
Ohlin, A. K., Holm, J., and Hillarp, A. (2004) Genetic variation in the human thrombomodulin promoter locus and prognosis after acute coronary syndrome. Thromb. Res. 113, 319326.

Rai, A. J., Kamath, R. M., and Gerald, W. (2009) Analytical validation of the GeXP analyzer and design of a workflow for cancer-biomarker discovery using multiplexed geneexpression profiling. Anal. Bioanal. Chem. 393, 1505-1511.

Rampal, L., Rampal, S., Azhar, M. Z., and Rahman, A. R. (2008) Prevalence, awareness, treatment and control of hypertension in Malaysia: A national study of 16,440 subjects. Public Health 122, 11-18.

Salazar, L. A., Hirata, M. H., Giannini, S. D., Forti, N., Diament, J., Lima, T. M., and Hirata, R. D. C. (2000) Seven DNA polymorphisms at the candidate genes of atherosclerosis in Brazilian women with angiographically documented coronary artery disease. Clin. Chim. Acta 300, 139-149.

Salomaa, V., Matei, C., Aleksic, N., Sansores-Garcia, L., Folsom, A. R., Juneja, H., Park, E., and Wu, K. K. (2001) Crosssectional association of soluble thrombomodulin with mild peripheral artery disease; the ARIC study. Atherosclerosis 157, 309-314.

Seo, D., Wang, T., Dressman, H., Herderick, E. E., Iversen, E. S., Dong, C., Vata, K., Milano, C, A., Rigat, F., Pittman, J., et al. (2004) Gene expression phenotypes of atherosclerosis. Arterioscler. Thromb. Vasc. Biol. 24, 1922-1927.

Spagnoli, L. G., Bonanno, E., Sangiorgi, G., and Mauriello, A. (2007) Role of inflammation in atherosclerosis. J. Nucl. Med. 48, 1800-1815.

Sukhova, G., Schonbeck, U., Rabkin, E., Shoen, F. J., Poole, R., Billinghurst, R. C., and Libby, P. (1999) Evidence for increased collagenolysis interstitial collagenases- 1 and -3 in vulnerable human atheromatous plaques. Circulation 99, 2503-2509.

ten Dijke, P., and Arthur, H. M. (2007) Extracellular control TGF $\beta$ signalling in vascular development and disease. Nat. Rev., Mol. Cell Biol. 8, 857-869.

Tveten, K., Strøm, T. B., Cameron, J., Holla, Ø. L., Berge, K. E., and Leren, T. P. (2012) Characterization of a naturally occurring degradation product of the LDL receptor. Mol. Genet. Metab. 105, 149-154.

Vansant, G., Pezzoli, P., Saiz, R., Birch, A., Duffy, C., Ferre, F., and Monforte, J. (2006) Gene expression analysis of troglitazone reveals its impact on multiple pathways in cell culture: A case for in vitro platforms combined with gene expression analysis for early (idiosyncratic) toxicity screening. Int. J. Toxicol. 25, 85-94.

Varga, E. A., Sturm, A. C., Misita, C. P., and Moll, S. (2005) Homocysteine and MTHFR mutations: relation to thrombosis and coronary artery disease. Circulation 111, e289e293.

Wang, L., Ma, Y., Xie, X., Yang, Y., Fu, Z., Liu, F., Li, X., and Chen, B. (2011) Association of MMP-9 gene polymorphisms with acute coronary syndrome in the Uygur population of China. World J. Emerg. Med. 2, 104-110.

Werba, J. P., Martinez, V., Abulafia, D. P., Levy, R., Magariños, G., Rey, R. H., Baetta, R., Soma, M. R., Añel, A. D., and Cuniberti, L. A. (2001) Marked neointimal lipoprotein lipase increase in distinct models of proclivity to atherosclerosis: a feature independent of endothelial layer integrity. Atherosclerosis 156, 91-101.

Zhao, J., Zhou, X., Huang, J., Chen, J., and Gu, D. (2005) Association study of the thrombomodulin $-33 \mathrm{G}>\mathrm{A}$ polymorphism with coronary artery disease and myocardial infarction in Chinese Han population. Int. J. Cardiol. 100, 383-388. 